\title{
Is EPILEPSY A CAUSE OF COGNITIVE DECLINE IN DEVELOPING BRAIN
}

\author{
Ashima Nehra*1, Manjari Tripathi², Rohit Bhatia ${ }^{3}$, M.V. Padma Srivastava ${ }^{4}$, Mamta B. \\ Singh ${ }^{5}$, Sakshi Chopra ${ }^{6}$, Harsimarpreet Kaur $^{7}$, Swati Bajpai $^{8}$
}

${ }^{1}$ Department of Clinical Neuropsychology 1,6,7,8 \& Department of Neurology, ${ }^{2-5}$ All India Institute of Medical Sciences, New Delhi, India

\begin{abstract}
Epilepsy is a chronic noncommunicable disorder of the brain that affects people of all ages. Around 50 million people worldwide have epilepsy (WHO, 2012). 45,000 children under the age of 15, develop epilepsy each year (Epilepsy Foundation, 2010). Lower income was, however, associated with a higher incidence of epilepsy in all ethnic groups (Benn, et al., 2008). Neuropsychological impairment is an important co-morbidity of chronic epilepsy (Elger et al., 2004). Recent investigations have focused on the cumulative neurobiological burden associated with epilepsy and the risk of progressive cognitive impairment, but none have studied the effect of epilepsy on cognition on the developing brain, from India so far. Hence, the aim of the study was to study the effect of the temporal and extra temporal epilepsy on the cognitive functioning of children aged 7-12 years. Methodology: a cross-sectional study was carried out with a sample of 52 consenting children with an history of seizure (the 1st seizure occurred at least three months back i.e. the problem of seizure disorder was at least three months old) of neuropsychological assessment of epilepsy were administered with standardized neuropsychological tests, namely (Gesell's Drawing Test- by Verma et al., 1972, PGI-Memory Scale for children- by Kohli et al., 1998) Results indicated significant findings in nine areas of neuropsychological functioning, namely immediate recall $(p=0.001)$, followed by delayed recall $(p=0.001)$, attention and concentration $(p=0.001)$, recent memory $(p=0.001)$, remote memory $(p=0.001)$, visual retention $(p=0.001)$, retention for similar pairs $(p=0.001)$, mental balance $(p=0.001)$, recognition $(p=0.001)$ as compared to controls. Conclusion: results show that epilepsy does have a significant effect on cognition of children. However, a larger cohort study needs to be carried out to make substantiate claims.
\end{abstract}

Key words: Cognition; Epilepsy; Epidemiology; India; Memory; Neuropsychology

\section{INTRODUCTION}

Epilepsy is a common and diverse set of chronic neurological disorders characterized by seizures (Chang, 2003). Some definitions of epilepsy require that seizures be recurrent and unprovoked (U.S. National Library of Medicine, 2013), but others require only a single seizure combined with brain alterations which increase the chance of future seizures. Epileptic seizures result from abnormal, excessive or hypersynchronous neuronal activity in the brain. (American Academy of Neurology, 2012)

J.H. Jackson gave direction to the understanding of epilepsy in the late 19th century by carefully analyzing individual cases. From his observations, Jackson formulated the modern definition of epilepsy: "An occasional, excessive, and disorderly discharge of nerve tissue."

*Correspondence to: ashimanwadhawan@gmail.com

Received April 9; accepted August 20; Act Nerv Super (Praha) 55(3), 112-117. 
Jackson further concluded 'this discharge occurs in all degrees, it occurs with all sorts of conditions of ill health at all ages and under innumerable circumstances."

In clinical neuropsychology and cognitive sciences, "cognition" usually refers to an information processing view of an individual's psychological functions. It is also used in a branch of social psychology called social cognition to explain attitudes, attribution, and group's dynamics (Sternberg \& Sternberg, 2009). In cognitive psychology and cognitive engineering, cognition is typically assumed to be information processing in a participant's or operator's mind or brain (Blomberg, 2011). The core focus of cognitive psychology is on how people acquire, process and store information. There are numerous practical applications for cognitive research, such as improving memory, increasing decision-making accuracy and structuring educational curricula to enhance learning. Memory, in neuropsychology is the process by which information is encoded, stored, and retrieved. Encoding allows information that is from the outside world to reach our senses in the forms of chemical and physical stimuli. In this first stage we must change the information so that we may put the memory into the encoding process. Storage is the second memory stage or process. This entails that we maintain information over periods of time. Finally the third process is the retrieval of information that we have stored. We must locate it and return it to our consciousness. Some retrieval attempts may be effortless due to the type of information. (Greenberg, Rice, \& Elliott, 1996).

\subsection{Cognition and Epilepsy}

Neuropsychological tests traditionally assess function in five cognitive domains, all of which can dissociate in the pathological brain. These are intelligence, language, memory, perception and executive functions. A large number of skills comprise each domain. For example, memory tests can assess the learning, recall or recognition of different types of material presented during the testing session, in addition to long-term autobiographical recall and prospective memory skills. The distinction between declarative memory, (encompassing episodic memory - the recollection of experiences and episodes, and semantic memory knowledge of the world) and procedural memory (remembering how to do something, e.g. riding a bicycle) can also be made. Again, all of these abilities have been shown to dissociate in patients with focal lesions. (Helmstaedter, 2008).

\subsection{Cognitive Decline in Young Adults with Epilepsy}

It is well known that a subset of patients with epilepsy have some degree of cognitive impairment. The exact nature and severity of this impairment depends on many factors, including the age of seizure onset, the location of the seizure focus (in focal epilepsy) and the nature of the seizure disorder (e.g., focal versus generalized). Common cognitive complaints include memory and word-finding problems, although all cognitive domains can be affected. An additional question concerns whether this cognitive impairment is static or if it progresses over time. A recent review of longitudinal studies assessing cognitive change over time in patients with epilepsy has found that there is evidence for progression of cognitive deficits associated with chronic epilepsy (Seidenberg, Pulsipher \& Hermann, 2007). Specifically, several studies have found that compared to healthy controls, patients with epilepsy consistently fail to demonstrate practice effects on standard neuropsychological testing. That is, while the performance of healthy controls tends to improve with the second exposure to a given test, patients with epilepsy fail to improve. In addition, at least two studies have shown frank decline in cognition on repeat testing. (Høie et al, 2008, Oostrom, 2003). 
In patients with epilepsy, neuropsychological assessments are most frequently used to aid diagnosis, evaluate the cognitive side effects of antiepileptic medications and monitor the cognitive decline associated with some epileptic disorders. In conjunction with MRI and other pre-surgical investigations, neuropsychological scores are also used to assess the suitability of patients for epilepsy surgery and can be used to predict post-operative outcome, both in terms of cognitive change and seizure control.

\section{METHODS}

Objective: To assess the cognitive ability of children with epilepsy.

Hypothesis: Children with drug refractory epilepsy, both temporal and extra temporal lesions, will have cognitive impairment as compared to children without epilepsy.

Sample: A total sample of 56 were screened, out of which thirty four children with age range of 7-12 years, both males and females, right/left-handed, educated/uneducated coming from urban and rural backgrounds, diagnosed as having drug refractory epilepsy; both temporal and extra temporal lesions were assessed. These were patients who were referred to Clinical Neuropsychology for the assessment of cognitive functions, from the Department of Neurology in the Neurosciences Centre, which is now a part of routine service for Children suffering from epilepsy.

Inclusion criteria:

- Drug refractory epilepsy, both temporal and extra temporal

- $\quad$ Age Range: 7-12 years

- Both genders (Efforts were made for equal boys and girls)

- All education levels

- Urban and rural

- Right/left handedness

- Consenting individuals

\section{Exclusion Criteria:}

- Mental Retardation (IQ<70) (WHO, 1995)

- Above the age of 12 years

- Below the age of 7 years

- Any history of psychiatric illness

- Acute head injury

- Any acute systemic illness

- Those not consenting

Tools:

1. Gesell Drawing Test: By Verma et al. (1972)

It is a screening test of intellectual ability usually used for children to find out their approximate Mental Age. There are 9 designs which are to be copied exactly by the child, and each design correctly copied gives an approximate age of mental functioning (Mental Age).

2. PGI Memory Scale for Children: By Kohli et al. (1998)

It is a standardized Indian tool for evaluating the cognitive and memory ability. Its subscales are: Recent Memory, Remote Memory, Attention and concentration, immediate recall, Delayed recall, Retention for Similar pairs, Retention for dissimilar pairs, mental balance, visual retention and recognition. (Table 1)

Procedure for data collection: Patients with drug refractory epilepsy, both temporal and extra temporal, taking treatment at the Department of Neurology at the Neurosciences Centre were referred to Clinical Neuropsychology for the assessment of cognitive functions. The patients were in the age range of 7-12 years. They were accompanied with their parents. These patients were assessed on a screening test of intellectual functioning using Gesell Drawing Test and then were assessed on a series of cognitive functioning tests, using PGI Memory Scale for children. Consent forms were signed by the parents of these children, declaring having no problem with being part of the study. 
Table 1. Memory Scale for Children.

\begin{tabular}{|c|c|c|}
\hline $\begin{array}{l}\text { S. } \\
\text { NO. }\end{array}$ & TEST & FUNCTION \\
\hline 1 & \multirow{10}{*}{$\begin{array}{l}\text { PGI Memory Scale for } \\
\text { Children (Kohli et al., 1998) }\end{array}$} & Recent Memory \\
\hline 2 & & Remote Memory \\
\hline 3 & & Attention And Concentration \\
\hline 4 & & Immediate Recall \\
\hline 5 & & Delayed Recall \\
\hline 6 & & Retention For Similar Pairs \\
\hline 7 & & Retention For Dissimilar Pairs \\
\hline 8 & & Mental Balance \\
\hline 9 & & Visual Retention \\
\hline 10 & & Recognition \\
\hline
\end{tabular}

\section{RESULTS}

A total of 52 children from November 2012 to March 2013 were referred to assess the cognitive functioning of the developing brains, suffering from seizures (temporal and extra temporal epilepsy). They were diagnosed as having epilepsy using the diagnostic criteria given by the International League Against Epilepsy (ILAE, 2010) used by the neurologist as an outpatient service (O.P.D). Out of the 52 children, (between the age ranges of 7-12 years) only 34 could be evaluated for their cognitive domains since their intellectual ability/ functioning was average/dull normal, which was assessed as a routine using Intellectual screening by Gesell's drawing test (Verma et al., 1972).

Table 2. Results of cognitive tests in children with epilepsy.

\begin{tabular}{|c|c|c|c|c|c|}
\hline \multirow[t]{2}{*}{ Cognitive Tests } & \multirow{2}{*}{$\begin{array}{l}\text { Cognitive } \\
\text { Function }\end{array}$} & \multicolumn{2}{|c|}{$\begin{array}{l}\text { Epileptics } \\
(\mathbf{N}=\mathbf{3 4})\end{array}$} & \multirow{2}{*}{$\begin{array}{c}\mathbf{t} \\
\text { Value }\end{array}$} & \multirow[t]{2}{*}{$\mathbf{p}$} \\
\hline & & Mean & $S D$ & & \\
\hline Recent Memory & Ability to remember past events & 3.88 & \pm 1.53 & 5.48 & 0.001 \\
\hline Remote Memory & $\begin{array}{l}\text { Ability to remember information } \\
\text { from minutes, hours, or days ago }\end{array}$ & 3.91 & \pm 1.15 & 4.09 & 0.001 \\
\hline $\begin{array}{l}\text { Attention and } \\
\text { Concentration }\end{array}$ & Directed \& sustained & 6.44 & \pm 2.28 & 7.19 & 0.001 \\
\hline Immediate Recall & $\begin{array}{c}\text { Ability to remember events } \\
\text { occurring within the past few minutes }\end{array}$ & 7.88 & \pm 2.61 & 11.34 & 0.001 \\
\hline $\begin{array}{l}\text { Delayed } \\
\text { Recall }\end{array}$ & $\begin{array}{l}\text { Ability to remember something after } \\
\text { a period of rest or distraction ranging } \\
\text { anywhere from minutes to days }\end{array}$ & 5.08 & \pm 2.09 & 7.64 & 0.001 \\
\hline $\begin{array}{l}\text { Retention For } \\
\text { Similar Pairs }\end{array}$ & Simple learning ability & 6.52 & \pm 2.31 & 3.71 & 0.001 \\
\hline $\begin{array}{l}\text { Retention For } \\
\text { Dissimilar Pairs }\end{array}$ & New learning ability & 3.88 & \pm 1.24 & 0.83 & 0.40 \\
\hline Mental Balance & Temporal sequencing & 9.44 & \pm 4.02 & 3.03 & 0.001 \\
\hline Visual Retention & Ability for visual memory & 8.17 & \pm 4.24 & 3.70 & 0.001 \\
\hline Recognition & $\begin{array}{c}\text { Ability to recognize previously } \\
\text { encountered events, objects, or people }\end{array}$ & 7.29 & \pm 3.06 & 2.90 & 0.001 \\
\hline
\end{tabular}


They were further assessed on cognitive functioning including: recent memory, remote memory, mental balance, attention and concentration, delayed recall, immediate recall, retention for similar pairs, retention for dissimilar pairs, visual retention and recognition, using PGIMS for children (Kohli et al., 1998). These were patients who had their first seizure at least 6 months earlier than the date of assessment. Eighteen children who had mental retardation (mild to profound mental retardation) were excluded from the study. Results of the 34 children were further compared to the norms (Kohli et al., 1998) showing that the cognitive functioning was most impaired in immediate recall $(t=11.34)$, followed by delayed recall $(t=7.64)$, attention and concentration $(t=7.19)$, recent memory $(t=5.48)$, remote memory $(t=4.09)$, visual retention $(t=3.70)$, retention for similar pairs $(t=3.71)$, mental balance $(t=3.03)$, recognition $(\mathrm{t}=2.90)$ and retention for dissimilar pairs $(\mathrm{t}=0.83)$ respectively. The results revealed that all these areas of cognition except retention for dissimilar pairs (ability for new learning) had a significant difference with the norms, indicating that these children with seizure disorder had significant cognitive impairment in comparison to their age related controls.

\section{DISCUSSION}

Any event may cause problems in the developing brain. Some of these may have a permanent/long lasting effect. This problem may range from intellectual impairment (Levin, et al 1982) or cognitive deficits (Gauthier, et al., 2006; Nolan et al., 2004; Hommet et al., 2006). Information on this aspect from India is limited to only intellectual functioning and epilepsy (Sanyal et al., 2005). On the bases of extensive literature review, unfortunately there were no studies from India regarding the effect of seizure disorder on cognitive functioning on developing brains. Seizure disorder has been found to effect the cognitive functioning

found in the present study showing that various different abilities, which are a part of cognition, such as the ability to remember past events, the ability to remember information from minutes, hours, or days ago, the ability of temporal sequencing, attention \& concentration (directed \& sustained), ability to remember events occurring within the past few minutes, ability to remember something after a period of rest or distraction ranging anywhere from minutes to days, simple learning ability, ability for visual memory and ability to recognize previously encountered events, objects, or people. Periodical neuropsychological (including intellectual functioning and cognitive functioning in developing brain) evaluation and role of drugs on different types of seizure disorders may go a long way in planning pharmacological management of the children.

To conclude, information on cognitive functioning of developing brains in seizure disorder cases is an essential knowledge for their future. This study shows that there is probably a significant relationship between cognitive functioning and seizure disorder. But there is a need to study the same aspect in all types of epilepsy, including other aspects like, socio-demographic details (cultural, economic, social, family background, urban rural, religion etc), medicine and social support. Hence, a larger sample may confirm inferences. These cases highlight the importance that early diagnosis and management may lead to favourable outcome in children with seizure disorder.

Limitations and future direction: Ours was a small sample to make inferences; hence we plan to do a formal large cohort Indian study, in order to find a specific relationship between different types of epilepsy, the drugs administered, drug interaction and their effect on neuropsychological (intellectual, cognitive) functioning. In addition, these patients need to be studied in long term follow up as a cohort study to see if these cognitive disorders improve automatically in developing brains. Hence, extensive Indian neuropsychological researches can be undertaken in this area. 


\section{REFERENCES}

All, W. H. O. (1995). Diagnostic and statistical manual of mental disorders.

Benn, Ek., Hauser, Wa., Shih, T. et al. (2008). Estimating the incidence of first unprovoked seizure and newly diagnosed epilepsy in the low-income urban community of Northern Manhattan, New York City. Epilepsia, 49, 1431-9.

Blomberg, O. (2011). Conceptions of Cognition for Cognitive Engineering. The International Journal of Aviation Psychology, 21(1), 85-104.

Chang B.S., Lowenstein D.H. (2003). Epilepsy. New England Journal of Medicine, 349 (13), 1257-66.

Elger, C. E., Helmstaedter, C., \& Kurthen, M. (2004). Chronic epilepsy and cognition. The Lancet Neurology, 3(11), 663-672.

Epilepsy Foundation. Fact Sheet (2010). Epilepsy Therapy Project. http://www.epilepsyfoundation.org/aboutepilepsy/whatisepilepsy/statistics.cfm

Gauthier, S., Reisberg, B., Zaudig, M., Petersen, R. C., Ritchie, K., Broich, K., ... \& Winblad, B. (2006). Mild cognitive impairment. Lancet, 367(9518), 1262-1270.

Greenberg, L. S., Rice, L. N., \& Elliott, R. (1996). Facilitating emotional change: The moment-by-moment process. The Guilford Press.

Høie, B., Sommerfelt, K., Waaler, P. E., Alsaker, F. D., Skeidsvoll, H., \& Mykletun, A. (2008). The combined burden of cognitive, executive function, and psychosocial problems in children with epilepsy: a population - based study. Developmental Medicine \& Child Neurology, 50(7), 530-536.

Hommet, C., Sauerwein, H. C., De Toffol, B., \& Lassonde, M. (2006). Idiopathic epileptic syndromes and cognition. Neuroscience \& Biobehavioral Reviews, 30(1), 85-96.

ILAE, L. A. E. (2010). EDITORIAL POLICIES. Epilepsia, 51(9), 1923-1932.

Jackson, HJ. (1981) On temporary mental disorders after epilepsy paroxysms. In Taylor J, ed. Selected Writings of John Hughlings Jackson. Vol 1. London: Hodder and Stonghton: 119-134

Kohli, A. (1998). Measurement of Memory in Children: Construction of a simple clinical tool in Hindi, PGIMER, Chandigarh.

Levin, H. S., Eisenberg, H. M., Wigg, N. R., \& Kobayashi, K. (1982). Memory and intellectual ability after head injury in children and adolescents. Neurosurgery, 11(5), 668-673.

Nolan, M. A., Redoblado, M. A., Lah, S., Sabaz, M., Lawson, J. A., Cunningham, A. M.,. \& Bye, A. M. (2004). Memory function in childhood epilepsy syndromes. Journal of Paediatrics and Child Health, $40(1-2), 20-27$.

Oostrom, K. J., Smeets-Schouten, A., Kruitwagen, C. L., Peters, A. B., \& Jennekens-Schinkel, A. (2003). Not only a matter of epilepsy: early problems of cognition and behavior in children with "epilepsy only" - a prospective, longitudinal, controlled study starting at diagnosis. Pediatrics, 112(6), 13381344.

Sanyal, S.K., Chandra, P.S., Gupta, S., Tripathi, M., Singh, V.P., Jain, S., Padma. M.V., Mehta, V.S. (2005). Memory and intelligence outcome following surgery for intractable temporal lobe epilepsy: relationship to seizure outcome and evaluation using a customized neuropsychological battery. Epilepsy Behavior 6(2), 147-55.

Seidenberg, M., Pulsipher, D., Hermann, B. (2007). Cognitive progression in epilepsy. Neuropsychology Review, 17, 445-454.

Sternberg, R. J., \& Sternberg, K. (2009). Cognitive psychology (6th Ed.). Belmont, CA: Wadsworth, Cengage Learning.

U.S. National Library of Medicine. 11 February 2013; http://www.nlm.nih.gov/medlineplus/epilepsy.html

Verma, S.K., Pershad, D. \& Kaushal, P. (1972) Gesell Drawing Tests as a measure of intelligence in the mentally retarded children. Indian Journal of Mental Retardation, 5, 64-68.

World Health Organization. Epilepsy Fact sheet No999 October 2012 http://www.who.int/mediacentre/factsheets/fs999/en/ 